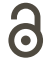

OPEN ACCESS

EDITADO POR

- Marcus Maia (UFRJ)

- Bruna Franchetto (UFRJ)

REVISADO POR

- Ana Vilacy Galucio (UFPA)

- Marcia Dámaso Vieira (UFRJ)

DATAS

- Recebido: 19/05/2020

- Aceito: 11/09/2020

- Publicado: 27/11/2020

COMO CITAR

TAPIRAPÉ, Nivaldo Korira'i. (2020). Os rituais Apyãwa mantêm e preservam a língua e suas histórias. Cadernos de Linguistica, v. 1, n. 3, p. 01-11.
RELATO DE EXPERIÊNCIA

\section{OS RITUAIS APYÃWA MANTÊM E PRESERVAM A LÍNGUA E SUAS HISTÓRIAS}

\author{
Nivaldo Korira'i TAPIRAPÉ (D) \\ Programa de Pós-Graduação em Educação em Contexto Indígena \\ Intercultural - UNEMAT | Escola Indígena Estadual Tapi'itãwa
}

\section{RESUMO}

O presente artigo tem como propósito apresentar uma experiência de vida exemplar do povo Apyãwa -Tapirapé que habita a região nordeste do estado de Mato Grosso. Trata-se de uma experiência que serve para reflexão sobre a manutenção de língua materna e cultura do povo. Este trabalho mostra que preservar uma língua é muito mais do que "falar" e, sim, é fortalecer e valorizar o conhecimento que ela produz, que se considera a base de todas as sabedorias indígenas ou de uma sociedade. Neste artigo, focalizando a linguagem dos rituais, abordamos a língua como um dos patrimônios principais de um povo indígena que mantém vivas as suas práticas culturais. O povo Apyãwa é sobrevivente de um desastre, que quase o levou à extinção étnica, linguística e cultural no século passado, e hoje tem uma experiência fantástica para dialogar com outros povos as estratégias de sobrevivência física, linguística e cultural. Abordamos também a escola como um instrumento e ferramenta fundamental que apoia esse trabalho de direcionamento do projeto de futuro da comunidade Apyãwa, de manutenção dos rituais e de nossa língua.

\section{ABSTRACT}

The purpose of this article is to present an exemplary life experience of the Apyãwa -Tapirapé people who inhabit the northeastern region of the state of Mato Grosso. It is an experience that serves to reflect on the maintenance of the native language and culture of the people. This work shows that preserving a language is much more than "speaking" and, 
yes, it is strengthening and valuing the knowledge it produces, which is considered the basis of all indigenous knowledge or of a society. In this article, focusing on the language of rituals, we approach language as one of the main assets of an indigenous people who keep their cultural practices alive. The Apyãwa people are survivors of a disaster that almost led them to ethnic, linguistic and cultural extinction in the last century, and today they have a fantastic experience to dialogue with other peoples on strategies for physical, linguistic and cultural survival. We also approach the school as a fundamental instrument and tool that supports this work of directing the Apyãwa community's future project, of maintaining rituals and our language.

PALAVRAS-CHAVE

Povo Apyãwa; Língua e Cultura; Rituais.

\section{KEYWORDS}

Apyãwa People; Language and Culture; Rituals. 


\section{INTRODUÇÃO}

O povo Apyãwa - Tapirapé, pertencente à família linguística Tupi-Guarani, habita a região Nordeste do estado de Mato Grosso. O povo atualmente vive em duas áreas indígenas: Terra Indígena Urubu Branco e Área Indígena Tapirapé /Karajá. Nesses territórios estão distribuídas oito aldeias que são denominadas Tapi'itãwa. Akara'ytãwa, Wiriaotãwa, Towajaatãwa, Tapiparanytãwa, Myryxitãwa, Inataotãwa e Majtyritãwa, pertencendo aos municípios de Confresa, Porto Alegre do Norte, Santa Terezinha e Luciara, no Médio Araguaia. Atualmente, somam aproximadamente 900 indivíduos incluindo as populações das oito comunidades.

Este artigo tem como objetivo principal explicar a importância do conhecimento dos rituais como meios de enriquecimento, manutenção e preservação da linguagem original Apyãwa. O trabalho traz uma reflexão acerca da responsabilidade cultural e linguística, a valorização da sabedoria milenar indispensável para empoderamento da comunidade indígena. Os rituais são conhecimentos originários produzidos pela comunidade indígena que dão oportunidade para as gerações atuais vivenciarem a linguagem dos antepassados que, só através da sua prática, se torna presente. Os rituais produzem conhecimentos, os ensinamentos sobre os sentidos da vida cultural e histórica da comunidade.

O trabalho é inspirado em pesquisas sobre "Ka'o - Cantos dos pássaros", Trabalho de Conclusão de Curso de Licenciatura na Universidade do Estado de Mato Grosso - Unemat, Campus de Barra do Bugres - MT, elaborado em 2006 (N. Tapirapé, 2006). Uma fonte importante foi também o trabalho de Carlos Xario'i , que fez monografia na UNEMAT sobre os cantos Xakowi. Pesquisa sobre cantos Tapirapé também foi desenvolvida em 2019 com os alunos de Ensino Médio "Aranowa'yao" na Terra Indígena Urubu Branco, na qual foi aprofundado o conhecimento sobre os rituais de Myykipyra e Kawiaximynãwa. Junto com os alunos, fizemos trabalho em conjunto com os sábios e depois foram transcritos todos os cantos que estavam nas memórias dos cantores. Pretende-se retomar este trabalho nas oficinas para os jovens aprenderem a cantar os cantos próprios destes rituais.

Na seção 2, mostramos como os rituais contribuem para preservar a língua, pois possuem uma linguagem própria que guarda formas milenares, às vezes não mais praticadas, e como a prática dos rituais pode enriquecer a língua, trazendo de volta essas palavras para uso dos falantes. Na seção 3, apresentamos a importância dos rituais para manter viva na memória os fatos históricos da vida do povo e as narrativas míticas. O artigo conclui na seção 4. Considerações finais, destacando o papel central dos rituais para a transmissão de conhecimentos e manutenção da cultura e da língua e a importância do trabalho realizado na escola. 


\section{O RITUAL PRODUZ CONHECIMENTO E PRESERVA A LINGUAGEM}

Os rituais constituem um conjunto de conhecimentos importantes que a humanidade produziu desde a sua existência e que são compostos por uma linguagem própria. É um conhecimento que mais conserva e preserva a linguagem milenar e que, ao ser praticado, traz essa linguagem para ser apreciada pelos falantes da atualidade. Essa linguagem só se torna presente quando é praticada culturalmente, ou seja, só é usada e movimentada quando acontecem ações culturais e religiosas que, ao serem realizadas, também produzem significados para o seu usuário. Aqui vamos analisar o quanto este conhecimento é importante para manter presente as linguagens milenares e seus significados para a comunidade Apyãwa. Através desse conhecimento são apreciadas a língua e as formas de fala que foram presentes no passado na vida de nossos ancestrais. Se pararmos para analisar, veremos que alguns rituais são bastante resistentes quanto à sua modificação, ou seja, não permitem transformações em sua estrutura. São rituais intocáveis iguais às pedras, difíceis de serem desmanchados, diferentes de outros que podem ser reinventados e reconstruídos. Esses rituais geralmente merecem ter maior atenção, porque se seus usuários não compreenderem a sua importância, eles podem desaparecer e depois não poderão ser reinventados. Muitos desses rituais desapareceram porque as pessoas não aprenderam a cantar como, por exemplo, o ritual Xamã, Ireweeaxyga.

Ao analisarmos a situação atual dos rituais do povo Apyãwa, verificamos que isso ocorreu em muitos casos e, assim, desapareceram várias partes importantes das cerimônias. Podemos analisar, por exemplo, os rituais Kawiaximynãwa' e Myykipyra², que não são praticados há mais de trinta anos, mas, existem poucos sábios (as) que conhecem partes dos cantos. Porém, não se pratica esses rituais porque os chefes cerimoniais detêm apenas parte incompleta do canto e nessa situação não pode ser praticado. Para trazer de volta, são necessários muitos exercícios de memória para recuperar os cantos completos. Esses rituais geralmente têm os cantos apropriados do início e do fim que precisam ser seguidos pelo cantor. E tem mais, só as pessoas mais velhas que presenciaram a prática têm oportunidade de resgatar esses rituais, se não forem recuperados, este conhecimento será extinto.

Esses rituais precisam ter especialistas cerimoniais. Se não houver especialistas que dominam os cantos, eles serão extintos. Assim, mais rituais entrarão na lista de desaparecimento. O caso dos rituais Kawawawoo, Ireweeaxyga, está quase na mesma

1 Ritual de espírito, $3^{\mathrm{a}}$ iniciação do rapaz, que acontece quando o sol está entre a nossa cabeça.

2 Ritual de rapaz que acontece de dia, que inicia na takãra e faz contorno na aldeia. 
situação, porque existem apenas algumas pessoas que conhecem e a maioria não canta fluentemente o canto. Dessa forma, cada vez mais os rituais correm o risco de perderem a sua existência.

A grande parte dos rituais Apyãwa demonstra sua linguagem específica que transmite mensagens e significado de algumas coisas. Ka'o, Marakayja e Axywewoja são alguns exemplos importantes que mostram claramente a presença destes conhecimentos do povo Apyãwa. Quando analisamos profundamente o contexto das palavras, verificamos que existem várias palavras antigas que só os rituais mantêm vivas através dos seus cantos. Dá para verificar que a língua se modificou com o passar do tempo, pois ela não se mantém parada como a pedra. Até os falantes fluentes da língua não conseguem interpretar estas palavras antigas. Só através da vivência dos rituais é possível dar vida para essa linguagem.

Existem algumas palavras que se modificam pouco e existem outras que são impossíveis de serem interpretadas, como podemos analisar neste trecho do canto de Kawio - Kawiypyparakãwa

(a) Kaweripe tewa

Parirãwaxa, parirawaxaã

A maioria dos cantos é de tempos imemoriais. O ritual é o meio de trazer a linguagem do passado para o presente. Analisando o trecho do canto (a) podemos perceber que no tempo do cotidiano atual não se usa mais esta linguagem, mas, não é impossível resgatar e vitalizar a linguagem para o nosso cotidiano, entendendo como ela é usada no ritual.

Por sua vez, no canto (b) o falante compreende algumas palavras e o contexto de que se trata.

(b) Amokwãraro, roamõ ewe - 'outro ano, quando vier' Araxapyykie raka wetywyrigewe - 'nós lutamos com meu irmão'

Paranyka'ã pe opixikaweripe tewa - 'rio na mata no momento do encontro'

O ritual só enriquece a linguagem quando é praticado, disponibilizando as palavras antigas para serem apreciadas pelos falantes. Analisando bem as estrofes dos cantos, algumas palavras não são mais faladas, por exemplo. Só são apreciadas durante a sua atualização durante a realização das cerimônias. Elas preservam seus cantos quando são cantadas pelos cantores. É incrível como um recurso tão forte dificilmente é acabado. Parece que estão guardados na memória de cada pessoa e assim, todos os anos, retomam a vitalidade nas festas cerimoniais. É de se admirar mesmo a capacidade da memorização do 
ser humano, pois as palavras dos cantos nunca estão escritas no papel, são movimentadas oralmente pelos cerimoniais.

No ritual de Marakayja existem noventa e uma músicas que são cantadas o dia inteiro. Marakayja é composto por quatro partes: Xawaromy. vinte e cinco cantos, Makaxi. vinte e quatro cantos, Marakapara. quatorze cantos e Maraka'yypa vinte e oito cantos que, assim, somam noventa e um cantos. São quatro partes de cantos que são memorizados e cantados pelos especialistas. A linguagem é totalmente especial e ancestral. Esses cantos têm que ser seguidos do início ao fim, seguindo a sequência correta. Este ritual não permite que se modifique sua linguagem. Assim também outros rituais como Marakao e Marakaxawãja que se praticam na festa do rapaz. Todos os cantos têm seu início e seu fim considerando a sua sequência. O rapaz, passando por esse processo da terceira iniciação, passa a ser adulto onde ele pode ser considerado homem maduro, que pode fazer o papel de homem, preparado para a vida do mundo Apyãwa. Significa, entre outras coisas, que ele pode comer aves que antes não podia comer nas fases da infância e da juventude.

No ritual de Kawio - Kawiypyparakãwa, a dupla que puxa o canto não pode, em nenhum momento, atropelar a sequência dos cantos e suas regras porque isso é considerado marawyna para os Apyãwa, quer dizer, produz um ato que incrimina a espiritualidade e a vida do povo. São conhecimentos e significados que o ritual produz que merecem ser respeitados por todos os membros da comunidade. Por isso, geralmente o Xamã acompanha todo o percurso do ritual, pois ele faz com que não aconteça nada de ruim com as pessoas. Este ritual serve para manter contato com os espíritos dos antepassados, uma vez que oportuniza a volta dos espíritos para fazer parte das festas. É um momento especial no qual os espíritos dos antepassados mortos se conectam aos meios dos espíritos vivos. Os espíritos presenciam o espaço dos vivos através da realização desses rituais.

\section{OS RITUAIS MANTÊM VIVAS AS NARRATIVAS MÍTICAS E AS HISTÓRIAS DO POVO}

Além da manutenção e preservação da linguagem usada na ancestralidade, o ritual traz para o presente as narrativas míticas e fatos históricos do povo Apyãwa. O ritual geralmente está articulado a uma narrativa mítica, por exemplo, Xeakygetaxiãwa ${ }^{4} 3^{\text {a }}$. iniciação masculina) e o mito Makaxiwewe. A maioria dos rituais transmite

\footnotetext{
4 O ritual de Iniciação do homem Apyãwa que acontece o dia todo com os cantos de Marakayja e a noite toda
} com Ka'o. 
conhecimentos que aconteceram no passado, por exemplo, a origem dos rituais que são praticados pelo povo.

No ritual de Marakayja é rememorado como o povo Apyãwa adquiriu conhecimento para a sua cultura. $\mathrm{O}$ inimigo que, ao mesmo tempo, trouxe este conhecimento para os Apyãwa estava dominado pelos guerreiros. Enquanto ensinava o ritual de Marakayja, estava sendo devorado vivo pelos ancestrais Apyãwa, ou seja, devorado simbolicamente. O herói desse ritual se chamava Xawaromy e seu filho Makaxiwewe. Depois de sacrificar o pai, o filho Makaxiwewe consegue fugir deixando seus pertences como enfeites e adornos que foram apropriados pelos Apyãwa e até os dias atuais são usados pelo rapaz que passa pelo ritual da terceira iniciação. Abaixo o canto de Marakayja, a primeira parte de Xawaromy e, na sequência, o canto de Makaxi.

(c) Herexowe rexowere

Herexowe, hererexowe, here

Apyawaxepeina pexokã xemykweri

Wyratywa axepeina pexokã xemykweri ramõ

Awaekakatonika aty naetyki wereka tewe

Apyawaxepeina pexokã - 'estão matando a última Apyãwa'

(d) Awaja'e'e

Apirog wekoxy'i

le kamorekweri apirog wekoxy'i

Awaja'e'e - 'quem sou eu'

Apirog wekoxy’i - 'eu contaminei minha mulher'

Analisando o contexto destes cantos, percebemos a presença da natureza e também a auto composição dos cantos mostra o acontecimento no momento exato em que o inimigo é transformado em alimento dos Apyãwa. O canto descreve-o sendo despedaçado e esquartejado vivo pelos inimigos enquanto cantava. Deste modo, foram ensinados aos Apyãwa os cantos, as regras e a preparação do rapaz para a última fase de iniciação que são celebradas nos rituais. Mostra também outras possibilidades de realização da festa de rapaz que são complementos da cerimônia como por exemplo, $M a$ rakao, marakaxawãja, Kawiaximynãwa.

O Kawiypyparakãwa, o mais importante ritual de Ka'o, trata de acontecimentos milenares do povo Apyãwa - Tapirapé. Nele são abordadas a importância da mulher e a previsão do futuro da comunidade. E ainda fala da arma como arco e flecha, como um instrumento importante para guerra, caças aos pássaros e animais. Mostra também a importância de Parany - rios e córregos naquela época. Os cantos demonstram também a importância de manter poder entre os grupos. Uma das atividades importantes que coloca é a luta corporal realizada durante os rituais. 
O Ka'otem uma infinidade de cantos, parece que a linguagem dos rituais corre no sangue dos cantores. Os homens cantam a noite toda e, muitas vezes, os cantores cuidam bastante para não repetir a mesma música, sempre buscando outros cantos diferentes. Segundo a mitologia Apyãwa, antigamente, este ritual não fazia parte do ciclo ritual Apyãwa Tapirapé, este foi introduzido por um antepassado Apyãwa que aprendeu diretamente com os pássaros. Ele conviveu com os pássaros e aprendeu como eles festejavam. Quando essa pessoa retornou para a sua comunidade, ensinou os cantos ao povo Apyãwa. Nos cantos do Ka'o, as palavras que mais aparecem nas composições das músicas são de axoro 'papagaio', kanine 'arara amarela', wyraxigoo'i 'garça', kojkoo 'inhuma', arakori 'galinha d'água', anoxyryry 'anu preto', inamo'i 'nambuzinha'. São cantos que impressionam as pessoas, pois têm forte ligação com os pássaros, como podemos ver a seguir:

(e) Wyraxigiãrimo, wyraxigiãrimo;

He'e e'e

Canto de Wyraxigoo'i ‘Garça'

(f) Ane pa ka ka'ema mõ ere,

Erexe'exe'ẽgine wyrã

Erexe'exe'ẽg wyrã

Hee'e ... xirikare, xirikakare

Xirikare, xirikakare.

Canto de Arakori 'Galinha d’água'

(g) Kojkooa'e 'e'e'e

Neakygetararõ pã ka ane wyraete ramõ

Kojkooa'e 'e wyrã kojkooa'ẽ

Kojkoo 'Inhuma'

Percebe-se de que, além de narrativas míticas, os rituais do Ka'oe Axywewoja, também revelam fatos históricos recentes como contatos com outros povos, fatos que marcaram a vida do povo Apyãwa. Nestes rituais é possível compreender que existem cantos ligados à mitologia e outros mais recentes que relatam fatos históricos que foram compostos pelos antigos Apyãwa. O conteúdo das músicas remete ao modo de falar dos antigos e aos acontecimentos do passado. Conforme apresentamos, a seguir, o ritual relata algum fato histórico que marca o acontecimento do passado. Um desses acontecimentos relatados nos rituais é a visita de outro povo na aldeia, então se conta a vida dos visitantes, como dormiam, como se comportavam. Os rituais contam sobre as guerras e conflitos interétnicos da região e no território que ocupavam, como este a seguir que revela o assassinato de um inimigo, um antepassado Karajá, quando um antigo se vingou dos visitantes. Esta aldeia ficou 
conhecida como aldeia Maakotãwa. Abaixo o canto de "Ka’o rerayrayjtãwa" que é o final do ritual.

(h) Kere, kere, kere, kerewie

Ane marapiãra mõ - 'você que veio'

Atã erepytã exata - 'veio parar aqui'

Akajnanowe xipa - 'imaginou que aconteceria a mesma'

Erejxe naka - 'é o que você imaginou"

Exe'egawera arewe - 'declarando para nós'

Enowakare'ymire ramexe naka. - 'que você demonstrou o que queria'

Até recentemente ainda encontramos alguns raros e importantes compositores do Ka'o. Existem cantos deles fazendo parte deste trabalho. A maioria dos cantos foi feita há cinquenta anos atrás pelos conhecedores de Ka'o. Vale a pena destacar aqui o nome de uma figura importante que foi Korawã, falecido na aldeia Maityritãwa. Ele fez muitas músicas que são cantadas atualmente. Ele foi um grande líder cerimonial do Ka'o dos anos cinquenta. Todo acontecimento importante, ele transmitia através do canto. Há momentos em que ele mesmo revela-se através do canto.

No canto de Axywewoja (rituais do verão), há uma infinidade de cantos que retratam, principalmente, fatos históricos, de conflitos, visitas de diferentes povos. E através destas músicas, sabemos também o passado que se transforma no presente da comunidade. Isso é muito importante para o povo. Se o ritual é vivo, praticado, as suas linguagens se manterão muito tempo presente nas práticas culturais, ao contrário, se esses rituais forem extintos ou não praticados mais, muitos conhecimentos se esvaziarão das territorialidades física e cultural do povo.

O canto traz fatos históricos, por exemplo, a visita dos não índios, no qual se descreve a fisionomia, a alimentação e o comportamento dos visitantes. Outro que chama atenção é o canto que registra o consumo de verduras. Os antigos imaginavam que eram folhas de anyrawaxarywa 'uma planta frutífera que o morcego come'. No ritual de Axywewoja todo mundo adora cantar esse canto. Revela também a visita de Paxawari, o mestiço que visitou a antiga aldeia Tapi'itãwa junto com a sua família, inclusive com sua filha Werearo. A seguir, veremos o canto do Xamã Koria elaborado na antiga Tapi'itãwa há 100 anos atrás.

(i) Ma'e tãwa pe pake amanõ ne pã;

Xoxekwereto pe ne pã

Weparararaka we'yna ne pã;

haaho haho;

Kana gy imano'ixewi, Kana gy imano'ixewi;

haaho haho.

Os versos dizem o seguinte: "não sabe quando morrerá. E se morrer, quem sabe no xoxekwereto", se refere ao local especial do xamã, porque outros morreram na frente dele. 
Quando ele fala "weparararaka we'yna ne pã" quer dizer, se refere à resistência do pajé. Outros acabam e ele sempre se renovará espiritualmente. O Koria era um pajé muito respeitado, ou seja, se fazia respeitar pelo povo pela ação espiritual. Se não houvesse Axywewoja, não presenciaríamos a história dele. Muitos antigos recentemente falecidos narravam muitas histórias sobre a vida dele na antiga Tapi'itãwa.

\section{CONSIDERAÇÕES FINAIS}

A cultura Apyãwa ainda é pouco conhecida na sociedade nacional e também para os próprios indígenas que a praticam, uma vez que muitos não compreendem com precisão todos os seus significados culturais. Muita sabedoria indígena no Brasil contemporâneo foi extinta por falta de atenção dos diversos governos, o que deixou em segundo plano a vida e a identidade de muitos povos. Cada povo indígena que vive hoje no Brasil é dono de universos culturais próprios. Sua variedade e sua originalidade são um patrimônio importante não apenas para eles próprios e para o Brasil, mas, de fato, para toda a humanidade.

As culturas e línguas são frutos da herança de gerações anteriores, mas estão sempre em eterna reconstrução, reelaboração, em desenvolvimento. Se não existissem os rituais, as culturas e as línguas poderiam desaparecer totalmente no tempo. Se pararmos para analisar palavras por palavras, dá para entender como o nosso povo se comunicava, e como, com o passar do tempo, essas palavras ou até mesmo as denominações de objetos ou outras coisas foram se modificando. Existem palavras na nossa língua que mudaram tanto que só os rituais as mantêm viva em todas as gerações. A maioria das palavras são irreconhecíveis e interpretáveis. Os rituais são práticas vitais das línguas ou palavras que não são mais faladas no cotidiano e só através de rituais estas palavras se tornam presentes.

Podemos dizer a mesma coisa sobre a importância do ritual sobre a transmissão de conhecimentos, a sabedoria, as narrativas míticas e fatos históricos do passado para o presente do povo Apyãwa. Nesse caso, os rituais necessitam de maior atenção para que não desapareçam, ou fiquem no esquecimento, e essa é uma responsabilidade social da comunidade Apyãwa. Necessitamos de muitos esforços para fortalecer os rituais que são praticados e revitalizar aqueles que estão em fase de extinção, como é o caso dos rituais Myykipyra, Kawiaximynãwa. É preciso buscar meios para trabalhar estes problemas com os jovens e toda a comunidade. No caso do Kawawoo e Ireweeaxyga é necessário um esforço para renovar os cantores. Nesse sentido, o trabalho de recuperação dos cantos feito com os jovens Apyãwa através da Escola Indígena Estadual Tapi'itãwa, tem-se mostrado como um meio excelente para revitalizar os rituais. Podemos afirmar que muitos jovens 
aprenderam os cantos de Ka’o nas aulas de música efetivadas no Ensino Médio e já demonstram este conhecimento para a comunidade durante a realização dos rituais.

Uma das finalidades deste trabalho é trazer para o povo Apyãwa, e quem sabe servirão também para outras comunidades indígenas, as reflexões sobre a importância dos rituais que podem ser discutidas também nas escolas indígenas. As escolas têm um papel importante para trabalhar estes temas, porque os jovens são as futuras gerações que poderão vivenciar estas práticas rituais.

\section{REFERÊNCIAS}

TAPIRAPÉ, Nivaldo Korira'i. Ka'o: canto da festa dos pássaros. Monografia de Conclusão de Curso de Ciências Sociais apresentada à UNEMAT, Campus de Barra do Bugres, 2006.

TAPIRAPÉ, Xario'i Carlos. Cantos do Xakowi. Monografia de Conclusão de Curso de Línguas, Artes e Literatura apresentada à UNEMAT, Campus de Barra do Bugres, MT, 2006. 